\title{
Further Evidence that Behavioral Tests and Neuropeptide mRNA and Tissue Level Alterations Can Differentiate between Typical and Atypical Antipsychotic Drugs
}

Richard Bauer, M.D., Adelcy Mayr, M.D., Wolfgang Lederer, M.D., Patricia L. Needham, B.Sc., Ian C. Kilpatrick, Ph.D., Wolfgang W. Fleischhacker, M.D., and Josef Marksteiner, M.D.

This study was designed to compare some behavioral and biochemical effects of chronic treatment with a range of antipsychotic drugs. Gene expression of enkephalin, chromogranin A, chromogranin B, and secretogranin II and their respective peptide products were studied with in situ hybridization and radioimmunoassays after daily oral administration of haloperidol, clozapine, risperidone, or zotepine for 21 days. In behavioral tests, significant catalepsy was induced by haloperidol only. All four antipsychotic drugs increased hind paw retraction time but only haloperidol also increased forelimb retraction time. In the caudate putamen, haloperidol increased both enkephalin $m R N A$ expression and enkephalin tissue levels. Neither of these parameters was altered by the other three drugs. In the prefrontal cortex, antipsychotic drugs generated a distinct pattern of gene expression in two regards. First, the dopamine $\mathrm{D}_{2}$ receptor antagonist, haloperidol, did not significantly alter synaptic protein levels or their encoding $m R N A s$. Secondly, there was a differential change in tissue levels and $m R N A$ expression since secretogranin II was not affected by any tested antipsychotic drug. This study shows that different types of antipsychotic drug induce distinct behavioural effects as well as differential changes in the biosynthesis of synaptic proteins and their encoding $m R N A s$. The data reinforce the notion that haloperidol can be classed as a typical antipsychotic drug whilst clozapine, zotepine, and risperidone reflect their atypical classification. [Neuropsychopharmacology 23:46-55, 2000] (C) 2000 American College of Neuropsychopharmacology. Published by Elsevier Science Inc. All rights reserved
KEY WORDS: Antipsychotic drugs; Neuropeptides; Chromogranins; Gene expression

Antipsychotic drugs are sometimes referred to as "atypical" if they demonstrate the ability to produce an antipsychotic action in most patients but with signifi-

From the Department of Pharmacology (RB), Department of Psychiatry (AM, WWF, JM), Department of Anaesthesiology and Intensive Care (WL), University of Innsbruck, Innsbruck, Austria; and Knoll Pharmaceuticals Research \& Development (PLN, ICK), Nottingham, England.

Address correspondence to: Josef Marksteiner, M.D., Department of Psychiatry, Anichstrasse 35, A-6020 Innsbruck, Austria. E-mail: j.marksteiner@uibk.ac.at

Received July 15, 1999; revised December 8, 1999; accepted December 27, 1999 . cantly less extrapyramidal side effects than classical (typical) antipsychotics (Fleischhacker and Hummer 1997). Lately, this distinction between "typical" and "atypical" antipsychotics has become the focus for much research aimed at establishing the pharmacological characteristics that serve to distinguish atypical antipsychotic drugs from the typical ones (Arnt and Skarsfeldt 1998). For example, in animals, acute and chronic treatment with these compounds causes distinct behavioral changes and alterations in the expression of different genes.

Alterations in the biosynthesis of synaptic proteins and their mRNAs can be used to investigate changes in neuronal activity following different neuronal stimuli 
(MacArthur and Eiden 1996). Haloperidol increases tissue levels of enkephalin and the expression of mRNA (Normand et al. 1987; Romano et al. 1987) in medium spiny striatal neurons which are associated with the dopamine 2 receptor (Le Moine et al. 1991) whereas clozapine, the prototypical "atypical" antipsychotic, does not induce catalepsy and does not lead to an increased enkephalin gene expression in the striatum (Mercugliano and Chesselet 1992). Consequently, antipsychotics which do not induce catalepsy appear unlikely to increase enkephalin biosynthesis (Augood et al. 1993; Mijnster et al. 1998). Therefore, both behavioral changes and a distinct pattern of gene expression may be used to predict an atypical profile for an antipsychotic compound.

The prefrontal cortex is an important brain area in schizophrenia research (Knable and Weinberger 1997; O'Donnell and Grace 1998). In animals, antipsychotic treatment causes an induction of immediate early genes in various brain areas including the prefrontal cortex. In this region, acute application of haloperidol or clozapine induces a differential expression of immediate early genes (Nguyen et al. 1992; Robertson and Fibiger 1992; Deutch and Duman 1996). Therefore, a different mechanism of action was postulated for haloperidol or clozapine treatment. However, most of these experiments investigated the induction of early genes after acute treatment.

Chromogranin A, chromogranin B, and secretogranin II belong to the chromogranin family which are large protein molecules found in large dense core vesicles. They are endoproteolytically processed to smaller peptides, and are released after neuronal stimulation (Huttner et al. 1991). The distribution of chromogranin B (Mahata et al. 1991; Kroesen et al. 1996), secretogranin II mRNA, and their immunoreactivity (Marksteiner et al. 1993a) have been studied in rat brains. The biosynthesis of chromogranins is regulated by different stimuli (Shen and Gundlach 1996). For example, ten days of treatment with clozapine or haloperidol led to significant changes in the biosynthesis of chromogranin B and secretogranin II mRNA (Kroesen et al. 1995).

In the present study, we have investigated behavioral and biochemical effects after chronic application of haloperidol, clozapine, risperidone, and zotepine. Due to their receptor binding profiles and their clinical effects, clozapine, risperidone, and zotepine are referred to as novel antipsychotics. All novel antipsychotics show a higher affinity for $5 \mathrm{HT}_{2 \mathrm{~A}}$ than for dopamine $\mathrm{D}_{2}$ receptors (Schotte et al. 1996). The aim of this study was three-fold. First, we were interested whether any of the test drugs could be distinguished by behavioural tests. Secondly, we investigated whether the expression pattern of chromogranins and enkephalin is suitable to predict an atypical antipsychotic profile. Lastly, we at- tempted to correlate neuronal mRNA expression to tissue concentrations of the respective peptides.

\section{MATERIALS AND METHODS}

Adult male Sprague-Dawley rats (Versuchstierzuchtanstalt, Himberg, Austria; body weight 225-250 g) were used for all experiments. Rats were maintained on a 12:12 h light/dark cycle with food and water available ad libitum. All procedures were done in accordance with the Austrian Guide for the Care and Use of Laboratory Animals and were approved by the local animal care committee.

\section{Drug Administration}

Animals $(n=16$ per treatment group and control group) received daily oral application for 21 days of vehicle (10 $\mu$ l of $\mathrm{N}$ glacial acetic acid per $1000 \mu \mathrm{l}$ of saline), haloperidol $(1 \mathrm{mg} / \mathrm{kg})$, clozapine $(20 \mathrm{mg} / \mathrm{kg})$, risperidone $(1 \mathrm{mg} / \mathrm{kg})$, or zotepine $(5 \mathrm{mg} / \mathrm{kg})$. Drug doses were chosen to reflect comparable multiples of (approximately $6 \times$ ED50s) for inhibition of amphetamineinduced hyperlocomotion (Leysen et al. 1993; Needham et al. 1996). The drugs were administered between 8.00 and 10.00, during the light cycle.

\section{Behavioral Testing}

All behavioral testing was performed between 8.00 and 10.00 , during the light cycle. In six out of sixteen animals, a behavioral testing was performed on days 5,10 , and 20 for the catalepsy. The paw test was applied on days 4,9 , and 19 . The animals which were behaviorally tested were not used for biochemical analysis.

Catalepsy. Catalepsy was tested using the standard horizontal bar method (Ezrin and Seeman 1977) at 90 minutes post-drug application. The animals were placed with the front paws on a horizontal metal bar which was suspended $10 \mathrm{~cm}$ above the benchtop. Time was recorded until one of the animal's paws touched the benchtop. The maximum immobility duration was set at 200 seconds.

Paw Test. Thirty and fifty minutes after the administration of the compound, each animal was submitted to the paw test. The paw test was performed as described by Ellenbroek and Cools (1988). Briefly, it was performed on a platform measuring $30 \times 30 \mathrm{~cm}$ with a height of $20 \mathrm{~cm}$. The platform contained four holes; two for the forelimbs and two for the hindlimbs. The rat was placed in the box and two dependent variables were 
scored; (i) forelimb retraction time (FRT); and (ii) hindlimb retraction time (HRT).

\section{Antisera}

The generation of the PE-11 antiserum was described previously (Kroesen et al. 1996). Briefly, it was generated against a synthetic peptide (PE-11) corresponding to rat chromogranin B 552-562 (Forss et al. 1989) which was identical to the human sequence. The antiserum only reacts with the free C-terminal part of PE-11 since an elongated peptide (chromogranin B 552-574) only reacts in the RIA when it is first subjected to trypsin digestion. No crossreactivity was found with peptides derived from chromogranin A and secretogranin II. It did also not cross-react with the following neuropeptides: galanin, substance $\mathrm{P}$, neuropeptide $\mathrm{Y}$, neurotensin, and calcitonin gene-related peptide.

The secretoneurin (rat secretogranin II 154-186 (Gerdes et al. 1988) antiserum was produced in rabbit. The production and specificity of the antiserum has been described previously (Kirchmair et al. 1993; Marksteiner et al. 1993a). It did not cross-react with chromogranin B or chromogranin A in Western blots. Synthetic peptides corresponding to the $\mathrm{N}$ - and C-terminus of secretogranin II did not cross-react in a specific radioimmunoassay for secretoneurin. Using radioimmunoassay, no significant cross-reactivity was detected with other peptides co-stored in large dense core vesicles, i.e., peptides derived from chromogranin A (LE40; WE-14), substance $P$, neuropeptide $Y$, and calcitonin gene related peptide.

\section{Tissue Extraction and Radioimmunoassay}

Twenty-four hours after the last drug treatment, five animals from each treatment group were decapitated and their brains were removed. The dorsolateral caudate putamen and prefrontal cortex were dissected according to the Atlas of Paxinos: (Paxinos and Watson 1986). The extraction procedure was performed as previously described (Marksteiner and Sperk 1988).

Specific radioimmunoassays for enkephalin, chromogranin B (PE-11) (Kroesen et al. 1996), and secretogranin II (secretoneurin) were performed as previously described (Marksteiner et al. 1993a) with slight modifications. Briefly, samples and standards were incubated with antiserum for 24 hours. Tracer was then added and probes were incubated for an additional 24 hours.

\section{In Situ Hybridization}

Five animals of each treatment group were killed by decapitation 12 hours after the final injection. The brains were rapidly removed, frozen in isopentane at $-65^{\circ} \mathrm{C}$ and stored at $-70^{\circ} \mathrm{C}$ until processing. Coronal cryostatcut sections $(20 \mu \mathrm{m})$ were thaw-mounted onto gelatincoated slides and stored at $-70^{\circ} \mathrm{C}$ until the day of the experiment. In situ hybridization was performed as described previously (Marksteiner et al. 1993b). Briefly, a synthetic oligonucleotide complementary to the bases 388-435 (NEP-502; New England Nuclear, Boston, MA) of prepro-enkephalin-A mRNA (Comb et al. 1982) was used. For chromogranin A, a 51-residue oligonucleotide corresponding to amino acids 1-17 (Iacangelo et al. 1988), for chromogranin B, a 54-mer based on amino acids 1-18 (Forss et al. 1989), and for secretogranin II, a 48residue oligonucleotide corresponding to amino acids 25-40 (Gerdes et al. 1988) was constructed. Oligonucleotides were labelled with terminal deoxynucleotidyl transferase and ${ }^{35} \mathrm{~S}-\alpha$-thio dATP $(1300 \mathrm{Ci} / \mathrm{mmol}$; NEN, Boston, MA). After hybridization, tissue sections and membrane standards were apposed to Hyperfilm- $\beta$ max autroradiographic film (Amersham, The Netherlands). Films were developed in Kodak 19 developer. After the quantification of the autoradiographic data, sections were dipped in Kodak NTB-2 photosensitive emulsion and exposed for seven weeks. After developing, the sections were counterstained with cresyl violet. In sections pretreated with ribonuclease A $(100 \mu \mathrm{g} / \mathrm{ml})$, only background labelling was observed.

\section{Quantification}

Quantification was performed on emulsion-coated sections. For each region, four sections were evaluated for each animal on emulsion-coated sections. Background grain density was measured over white matter. The number of labelled neurons per section within an area of $2.25 \mathrm{~mm}^{2}$ and the number of grains per labelled cell were counted with a grid at a magnification $\times 100$ or $\times 400$. The values were averaged for each animal. Five animals were included in each group. The mean values of untreated animals were compared to those of treated animals. Comparisons between control and treated groups were performed using one-way ANOVA followed by Dunnett's test to determine significant differences between these groups.

\section{RESULTS}

\section{Effects of Haloperidol, Clozapine, Risperidone, and Zotepine on Behavior}

As anticipated, treatment with haloperidol caused robust catalepsy in most animals (Table 1) although one animal did not demonstrate significant catalepsy. In contrast, none of the comparator antipsychotics induced catalepsy when animals were tested on days 4,9 , 
Table 1. Catalepsy Scores after Antipsychotic Treatment

\begin{tabular}{lcc}
\hline & \multicolumn{1}{c}{ 4 days } & 19 days \\
\hline Control & $4.3+3.7$ & $3.5+1.5$ \\
Haloperidol & $35.3+11.1^{* *}$ & $46.9+12.7^{* *}$ \\
Clozapine & $6.1+2.9$ & $5.3+3.2$ \\
Risperidone & $8.4+5.2$ & $12.4+5.7$ \\
Zotepine & $5.1+3.4$ & $4.5+2.8$ \\
\hline
\end{tabular}

Values represent seconds \pm S.E.M. Significant changes are indicated by asterisks: ${ }^{* *} p<.01$.

and 19. In the paw test, there was a significant difference between haloperidol and the effects of clozapine, risperidone and zotepine on each test day (Table 2). These latter three agents increased HRT without altering FRT, thereby increasing the HRT:FRT ratio. On the other hand, haloperidol increased both the FRT and HRT to similar extents without significantly altering the HRT:FRT ratio. No significant differences were found between the different days of testing.

\section{Enkephalin, Chromogranin A, Chromogranin B and Secretogranin II mRNA Expression and Respective Peptide Tissue Levels in the Caudate Putamen}

In the dorsolateral caudate-putamen, haloperidol treatment significantly increased both enkephalin-A mRNA expression and tissue levels (Figure 1; Tables 3 and 4). Neither mRNA expression nor peptide levels for enkephalin, chromogranin A, chromogranin B, or secretogranin II were significantly changed after clozapine, risperidone or zotepine treatment (Tables 3 and 4).

\section{Enkephalin, Chromogranin A, Chromogranin B and Secretogranin II mRNA Expression and Respective Peptide/Protein Tissue Levels in the Prefrontal Cortex}

Enkephalin-A mRNA could not be detected above the lower assay limits within the prefrontal cortex. Chro-

Table 2. The Effects of Antipsychotic Drugs on the Forelimb Retraction Time (FRT) and Hindlimb Retraction Time (HRT) as Measured with the Paw Test (see Materials and Methods)

\begin{tabular}{lcc}
\hline & FRT & HRT \\
\hline Control & $1+0.9$ & $2+1.4$ \\
Haloperidol & $13 \pm 4.3^{* *}$ & $14 \pm 5^{* *}$ \\
Clozapine & $1 \pm 1.4$ & $17 \pm 6.5^{* *}$ \\
Risperidone & $3 \pm 2.0$ & $13+4.9^{* *}$ \\
Zotepine & $2 \pm 1.5$ & $21 \pm 7.2^{* *}$
\end{tabular}

Data are represented as mean seconds \pm S.E.M. obtained at day $20 .{ }^{* *} p<$ .01 as compared to controls.
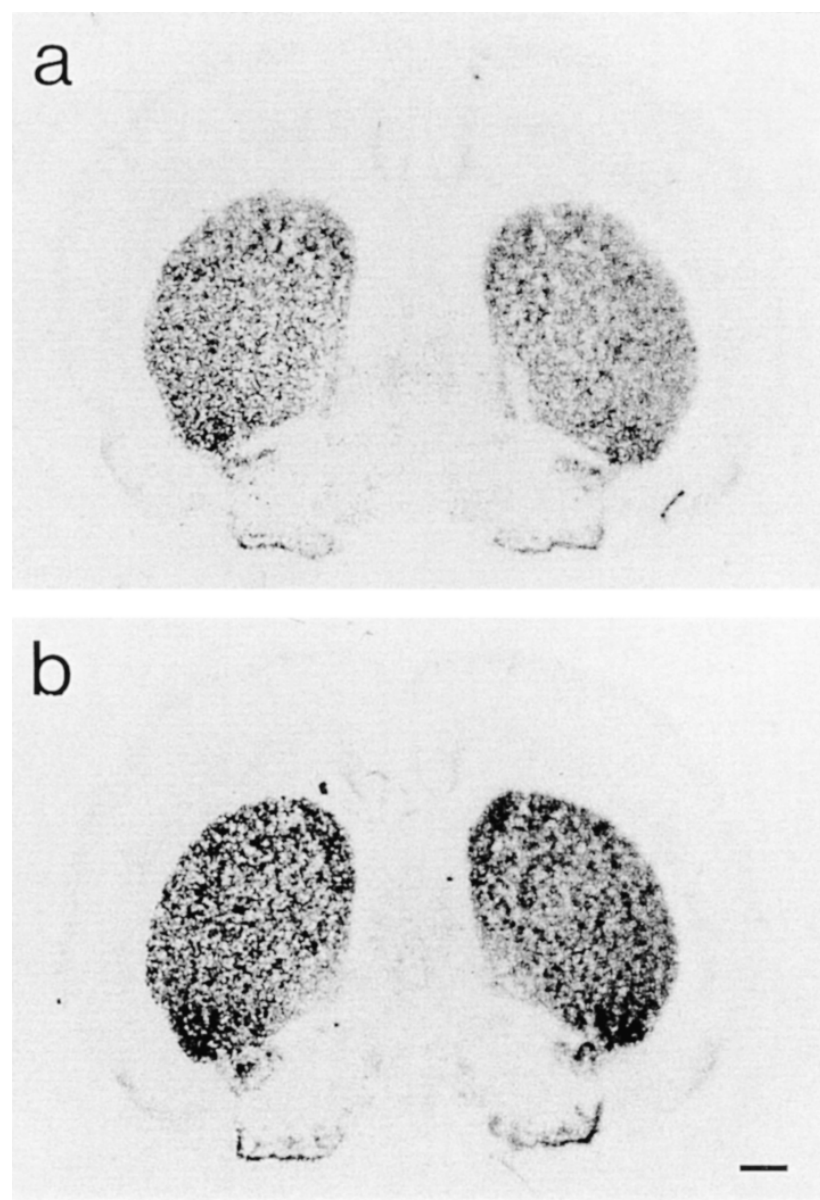

Figure 1. Autoradiograms for enkephalin-A mRNA in controls (a) and after haloperidol treatment at the level of rostral caudate putamen (b). Scale bar represents $1 \mathrm{~mm}$.

mogranin A mRNA containing neurons were preferentially found in cortical layers III and IV (Figure 2a). Chromogranin B was distributed throughout all layers with the highest number in layers III and IV (Figure 2c). Secretogranin II was found preferentially in layer II with scattered neurons in all other layers (not shown). Cellular chromogranin A mRNA expression was significantly reduced by chronic risperidone (Figures 2a and $2 \mathrm{~b}$; Table 3 ) and by clozapine treatment (Table 3). Tissue levels of chromogranin A were not determined. Risperidone (Figures 2c and 2d; Table 3) and zotepine treatment (Table 3) caused a significant decrease in the expression of chromogranin B mRNA.

Although neither clozapine nor haloperidol significantly reduced chromogranin B mRNA in prefrontal cortex, the PE-11-like immunoreactivity was significantly lowered by clozapine, risperidone, and zotepine and a strong trend to a decreased peptide level was also noted after haloperidol treatment $(p=.09)$ (Table 4). Neither secretogranin II mRNA transcript levels nor secretoneurin tissue levels were significantly altered by any of the drug treatments (Tables 3 and 4). The regions 
Table 3. Enkephalin, Chromogranin A, Chromogranin B and Secretogranin II mRNA Expression after Antipsychotic Treatment for 21 Days

\begin{tabular}{lllcrr}
\hline & & Enkephalin & Chr A & Chr B & Sg II \\
\hline Caudate putamen & Control & $100 \pm 6$ & $100 \pm 9$ & $100 \pm 4$ & $100 \pm 8$ \\
& Haloperidol & $127 \pm 5^{*}$ & $107 \pm 6$ & $98 \pm 2$ & $91 \pm 1$ \\
& Clozapine & $102 \pm 9$ & $106 \pm 10$ & $85 \pm 11$ & $114 \pm 7$ \\
& Risperidone & $113 \pm 2$ & $96 \pm 7$ & $84 \pm 6$ & $99 \pm 2$ \\
& Zotepine & $100 \pm 3$ & $103 \pm 2$ & $98 \pm 2$ & $109 \pm 7$ \\
Prefrontal cortex & Control & n.d. & $100 \pm 5$ & $100 \pm 4$ & $100 \pm 12$ \\
& Haloperidol & n.d. & $101 \pm 7$ & $86 \pm 3$ & $77 \pm 12$ \\
& Clozapine & n.d. & $75 \pm 2^{* *}$ & $88 \pm 5$ & $81 \pm 11$ \\
& Risperidone & n.d. & $50 \pm 8^{* *}$ & $70 \pm 6^{* *}$ & $111 \pm 8$ \\
& Zotepine & n.d. & $85 \pm 11$ & $77 \pm 4^{* *}$ & $107 \pm 13$ \\
\hline
\end{tabular}

Values represent silver grain densities (see Materials and Methods) and are expressed as percentage of control values (control \pm S.E.M.).

n.d., not detected; ${ }^{* *} p<.01$.

analyzed by in situ hybridization and radioimmunoassay are schematically shown in Figures 3a and 3b.

\section{DISCUSSION}

The present study reinforces the contention that typical and atypical antipsychotic drugs can be distinguished by behavioural and biochemical profiles. In the present study, these have included measures of catalepsy, paw retraction times, and distinct alterations in gene expression and synaptic peptide/protein production.

\section{Behavioural Measures}

In contrast to haloperidol, none of the reportedly atypical antipsychotic drugs induced catalepsy at any time point, consistent with the reduced extrapyramidal side- effects observed in the clinic with these drugs (Fleischhacker and Hummer 1997). In further contrast to haloperidol, the atypical drugs increased the ratio between forelimb and hindlimb retraction times, a feature that has been proposed as indicator of atypicality of these drug types (Ellenbroek and Cools 1988; Ellenbroek et al. 1994).

\section{Neurochemical Measures}

In the caudate putamen, the expression of both enkephalin mRNA and its tissue levels were increased after haloperidol but not after risperidone, clozapine or zotepine administration. These results are consistent with findings from many other groups who have demonstrated that typical—but not atypical-antipsychotics increase enkephalin content and mRNA levels in the caudate-putamen (Herman et al. 1991; Angulo 1992;

Table 4. Enkephalin-, PE-11 (Chromogranin B) and Secretoneurin (Secretogranin II) Tissue Levels after Antipsychotic Treatment

\begin{tabular}{llccc}
\hline & & Enkephalin & PE-11 & Secretoneurin \\
\hline Caudate putamen & Control & $100 \pm 9$ & $100 \pm 12$ & $100 \pm 15$ \\
& Haloperidol & $147 \pm 5^{* *}$ & $91 \pm 10$ & $83 \pm 13$ \\
& Clozapine & $98 \pm 7$ & $97 \pm 6$ & $91 \pm 9$ \\
& Risperidone & $107 \pm 6$ & $88 \pm 8$ & $82 \pm 11$ \\
Prefrontal cortex & Zotepine & $105 \pm 9$ & $102 \pm 14$ & $78 \pm 9$ \\
& Control & $100 \pm 1$ & $100 \pm 9$ & $100 \pm 14$ \\
& Haloperidol & $97 \pm 2$ & $75 \pm 9$ & $98 \pm 13$ \\
& Clozapine & $99 \pm 2$ & $63 \pm 5^{* *}$ & $92 \pm 8$ \\
& Risperidone & $95 \pm 1$ & $55 \pm 7^{* *}$ & $70 \pm 9$ \\
& Zotepine & $101 \pm 3$ & $56 \pm 7^{* *}$ & $93 \pm 10$ \\
\hline
\end{tabular}

Tissue levels (fmol/per mg wet weight) were determined 24 hours after the drug or vehicle application. In the prefrontal cortex, absolute values were for enkephalin $(7 \pm 1)$, for secretoneurin ( $32 \pm 4.5)$, and for PE-11 (42 \pm 3.8$)$. In the caudate-putamen of controls, absolute values were for enkephalin (164 \pm 15.3$)$, for secretoneurin $(49 \pm 7.4)$, and for PE-11 $(21 \pm 2.5)$. Data are shown as percent of the respective control group \pm S.E.M. ${ }^{* *} p<.01$. 

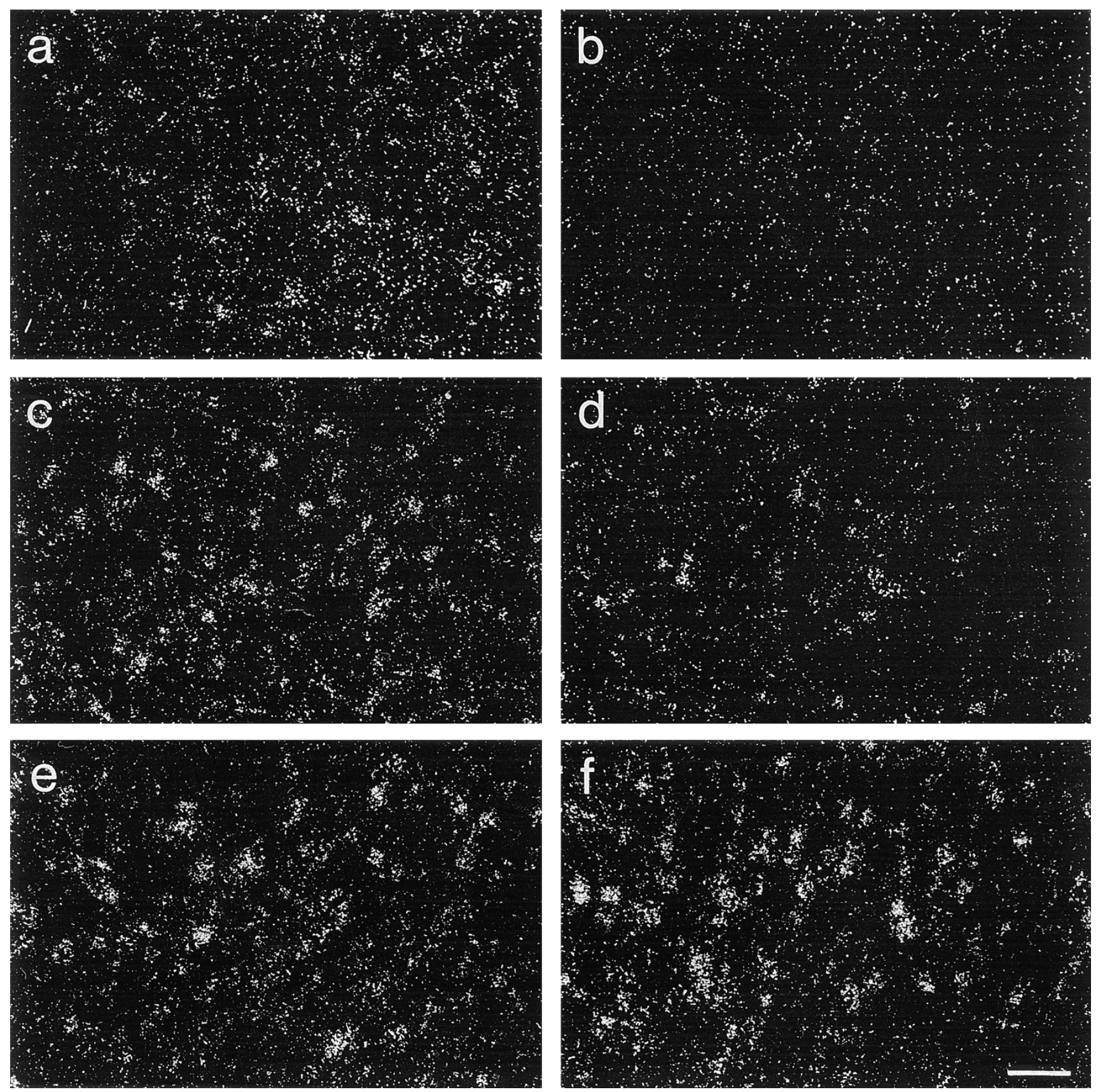

Figure 2. Darkfield photomicrographs of an aspect of the medial prefrontal cortex in controls (a, $\mathbf{c}, \mathbf{e})$ and after risperidone treatment $(\mathbf{b}, \mathbf{d}, \mathbf{f})$. Pictures are taken from a region of the prefrontal cortex shown in Figure 3 . The expression of chromogranin A shown in controls (a) is decreased after risperidone treatment (b). Chromogranin B containing neurons are shown in (c). After risperidone treatment a decrease in mRNA expression is observed (d). Secretogranin II expression in controls (e) is not significantly reduced after antipsychotic treatment with risperidone (f). Scale bar represents $75 \mu \mathrm{m}$.

Marksteiner et al. 1993b; Mijnster et al. 1996; Marin et al. 1996). However, haloperidol was the only typical antipsychotic used in this study. Therefore, future experiments testing several typical antipsychotics are necessary to further discriminate between typical and atypical antipsychotics and to characterize their effects on gene expression. For zotepine, this is the first report to show that this compound does not induce neuronal enkephalin mRNA expression or increased enkephalin tissue levels in the caudate putamen. The present findings therefore reaffirm the suggestion (Augood et al. 1993; Mijnster et al. 1998) that enkephalin gene expression in the caudate-putamen is either a marker for or plays a role in the development of extrapyramidal side- 
a) in situ hybridization

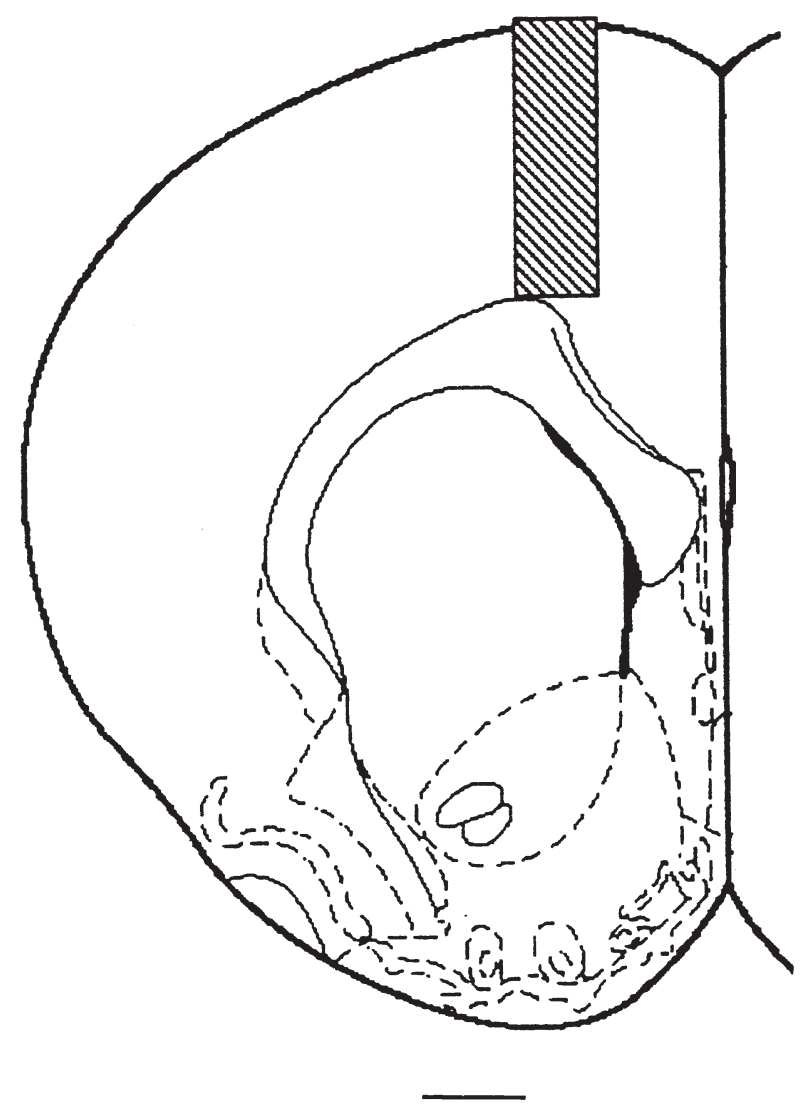

b) radioimmunoassay

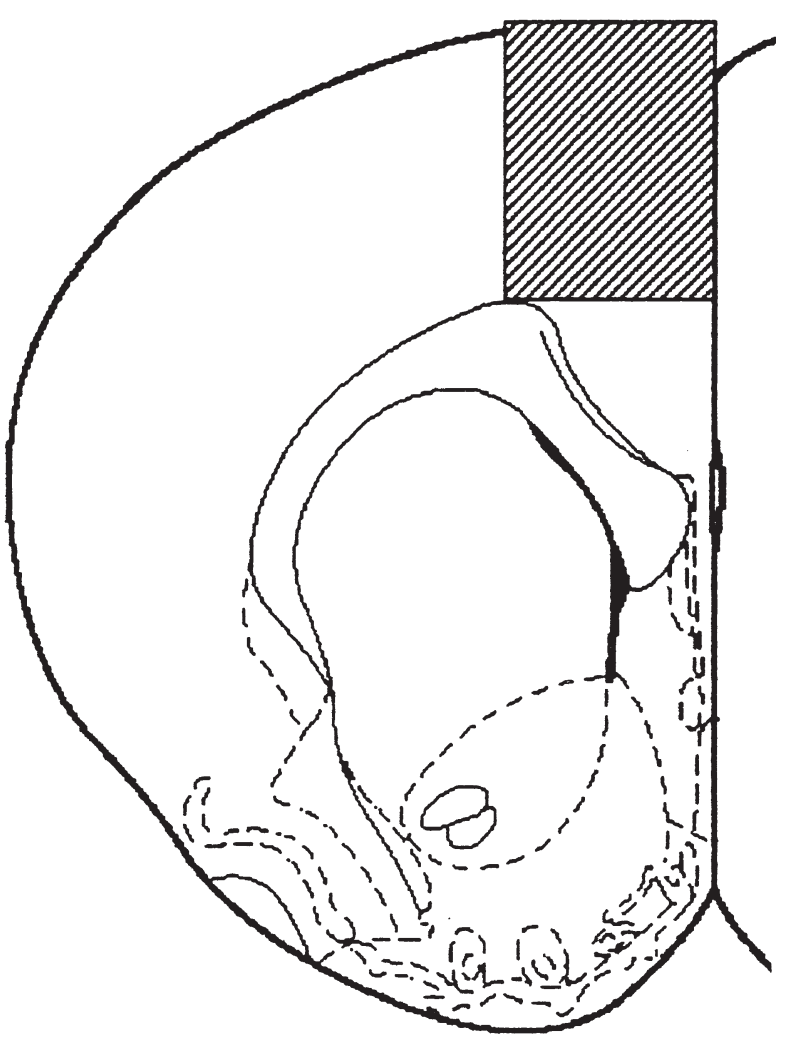

Bregma 1,70 mm

Figure 3. A schematic drawing according to the Atlas of Paxinos: (Paxinos and Watson 1986) indicates the region of prefrontal cortex analyzed by in situ hybridization (a) and radioimmunoassay (b). Four sections were sampled for in situ hybridization with a distance of about $400 \mu \mathrm{m}$ between each section. The schematic drawing represents the level of the third section. Scale bar represents $1 \mathrm{~mm}$.

effects associated with typical antipsychotic drugs. The lack of action of zotepine and clozapine on this parameter in the present study concurs with the atypical profile of these drugs both in animal models and in the clinic.

In the prefrontal cortex, antipsychotic drugs showed a distinct pattern on gene expression in two regards. First, haloperidol did not lead to any significant changes in synaptic proteins levels and in their encoding mRNAs. Secondly, in contrast to secretogranin II which was not affected by any antipsychotic drug, there was a change in tissue levels and mRNA expression of chromogranin A and B. In general, there was a good correspondence between decreased tissue levels and decreased expression of respective mRNAs. This indicates that decreased tissue levels are caused by a decreased expression of respective mRNAs in prefrontal cortex neurons rather than by an increased release of chromogranin A or chromogranin B.
The distinct effects of classical and novel antipsychotic drugs on synaptic proteins are in line with a differential induction of immediate early genes in the prefrontal cortex (Guo et al. 1998). Novel antipsychotic drugs, such as clozapine and olanzapine, caused an induction of these genes in acute experiments (Robertson et al. 1994; Deutch and Duman 1996; Robertson and Fibiger 1996). Repeated administration of typical versus atypical antipsychotic drugs leads to a region specific induction of deltaFosB (Atkins et al. 1999). In caudate putamen, typical antipsychotics cause a greater induction of deltaFosB than atypical antipsychotics (Hiroi and Graybiel 1996, Atkins et al. 1999).

What might be the reasons for changes in synaptic proteins? Clozapine, risperidone, and zotepine are more potent serotonin $2 \mathrm{~A}$ receptor antagonists than dopamine D2-like receptor antagonists. Haloperidol lacks 5-serotonin 2A properties. Therefore, the changes 
can not only be driven by dopamine effects. In contrast to haloperidol, clozapine as well as risperidone increase extracellular serotonin levels in medial prefrontal cortex (Ichikawa et al. 1998) which could influence the biosynthesis of chromogranins (Kroesen et al. 1995). What might be the consequences of changed chromogranin levels? Chromogranins are a family of regulatory secretory proteins. Their aggregation is promoted by calcium ions and low $\mathrm{pH}$, two parameters in the transGolgi network. There is now increasing evidence that chromogranins play an important role for sorting to secretory granules (Thiele and Huttner 1998). In the case of chromogranin B, reduction of the disulfide bond is sufficient to cause complete missorting of constitutive secretory vesicles (Chanat et al. 1993). Therefore, our experiments showing changes in chromogranin tissue levels may be of importance for the sorting of vesicles. Another important aspect is the capability of chromogranin deriving peptides to influence release of other vesicle constituents. It was recently shown that chromogranin A desensitizes catecholamine release (Mahata et al. 1999).

Alterations in synaptic proteins and their encoding mRNAs are reported in several brain areas including the prefrontal cortex of schizophrenic patients in the absence of gross structural abnormalities (Selemon and Goldman-Rakic 1999). The emerging picture of neuropathology in schizophrenia is one of subtle changes in cellular architecture and brain circuity (Lieberman et al. 1997) that nonetheless may have a devastating impact on cortical function. Antipsychotic drugs cause postsynaptic adaptations including regulation of neuronal gene expression leading to changes in synaptic protein content. Whether these results are of therapeutic relevance may depend on the neuronal system targeted by a particular drug (Hyman and Nestler 1996).

\section{CONCLUSIONS}

The present study shows that increases in enkephalin and its mRNA in the caudate-putamen can differentiate between typical and atypical antipsychotic drugs since they are not observed with atypical antipsychotic drugs. Conversely, similar increases in limbic regions occur irrespective of the side-effect profile of these antipsychotics and so may be linked to the therapeutic actions of these drugs. There is also evidence that chromogranins are sensitive and suitable markers to detect biochemical changes caused by chronic antipsychotic drugs. Expression patterns of some vesicle markers are distinctly altered depending on treatment with haloperidol or novel antipsychotic drugs.

\section{ACKNOWLEDGMENTS}

This work was supported by BASF Pharma/Knoll Pharmaceuticals Austrian Science Foundation (SFB F00206) and the Austrian National Bank (P 7150). The excellent technical assistance of I. Berger is gratefully acknowledged.

\section{REFERENCES}

Angulo JA (1992): Involvement of dopamine D1 and D2 receptors in the regulation of proenkephalin mRNA abundance in the striatum and accumbens of the rat brain. J Neurochem 58:110-1109

Arnt J, Skarsfeldt T (1998): Do novel antipsychotics have similar pharmacological characteristics? A review of the evidence. Neuropsychopharmacology 18:63-101

Atkins JB, Chlan-Fourney J, Nye HE, Hiroi N, Carlezon WA, Nestler EJ (1999): Region-specific induction of deltaFosB by repeated administration of typical versus atypical antipsychotic drugs. Synapse 33:118-128

Augood SJ, Westmore K, Faull RL, Emson PC (1993): Neuroleptics and striatal neuropeptide gene expression. Prog Brain Res 99:181-199

Chanat E, Weiss U, Huttner WB, Tooze SA (1993): Reduction of the disulfide bond of chromogranin B (secretogranin I) in the trans-Golgi network causes its missorting to the constitutive secretory pathways. EMBO J 12:2159-2168

Comb M, Seeburg PH, Adelman J, Eiden L, Herbert E (1982): Primary structure of the human met- and leu-enkephaline precursor of its mRNA. Nature 295:663-666

Deutch AY, Duman RS (1996): The effects of antipsychotic drugs on Fos protein expression in the prefrontal cortex: Cellular localization and pharmacological characterization. Neuroscience 70:377-389

Ellenbroek B, Cools AR (1988): The Paw Test: An animal model for neuroleptic drugs which fulfils the criteria for pharmacological isomorphism. Life Sci 42:1205-1213

Ellenbroek BA, Prinssen EP, Cools AR (1994): The role of serotonin receptor subtypes in the behavioural effects of neuroleptic drugs. A paw test study in rats. Eur J Neurosci $6: 1-8$

Ezrin WC, Seeman P (1977): Tolerance of haloperidol catalepsy. Eur J Pharmacol 41:321-327

Fleischhacker WW, Hummer M (1997): Drug treatment of schizophrenia in the 1990s. Achievements and future possibilities in optimising outcomes. Drugs 53:915-929

Forss PS, Danielson P, Battenberg E, Bloom F, Sutcliffe JG (1989): Nucleotide sequence and cellular distribution of rat chromogranin B (secretogranin I) mRNA in the neuroendocrine system. J Mol Neurosci 1:63-75

Gerdes HH, Phillips E, Huttner WB (1988): The primary structure of rat secretogranin II deduced from a cDNA sequence. Nucl Ac Res 16:11811

Guo N, Vincent SR, Fibiger HC (1998): Phenotypic characterization of neuroleptic-sensitive neurons in the fore- 
brain: Contrasting targets of haloperidol and clozapine. Neuropsychopharmacology 19:133-145

Herman ZS, Huzarska M, Kmieciak KK, Kowalski J (1991): Chronic treatment with chlorpromazine, thioridazine or haloperidol increases striatal enkephalins and their release from rat brain. Psychopharmacology (Berl) 104:106-112

Hiroi N, Graybiel AM (1996): Atypical and typical neuroleptic treatments induce distinct programs of transcription factor expression in the stratium. J Comp Neurol 374:70-83

Huttner WB, Gerdes HH, Rosa P (1991): The granin (chromogranin/secretogranin) family. TIBS 16:27-30

Hyman SE, Nestler EJ (1996): Initiation and adaptation: A paradigm for understanding psychotropic drug action. Am J Psychiatry 153:151-162

Iacangelo A, Okayama H, Eiden LE (1988): Primary structure of rat chromogranin $\mathrm{A}$ and distribution of its mRNA. FEBS Lett 227:115-121

Ichikawa J, Kuroki T, Dai J, Meltzer HY (1998): Effect of antipsychotic drugs on extracellular serotonin levels in rat medial prefrontal cortex and nucleus accumbens. Eur J Pharmacol 351:163-171

Kirchmair R, Hogue-Angeletti R, Gutierrez J, Fischer-Colbrie R, Winkler H (1993): Secretoneurin-a neuropeptide generated in brain, adrenal medulla and other endocrine tissues by proteolytic processing of secretogranin II (chromogranin C). Neuroscience 53:359-365

Knable MB, Weinberger DR (1997): Dopamine, the prefrontal cortex and schizophrenia. J Psychopharmacol 11:123-131

Kroesen S, Marksteiner J, Leitner B, Hogue Angeletti R, Fischer Colbrie R, Winkler H (1996): Rat brain: distribution of immunoreactivity of PE-11, a peptide derived from chromogranin B. Eur J Neurosci 8:2679-2689

Kroesen S, Marksteiner J, Mahata SK, Mahata M, Fischer Colbrie R, Saria A, Kapeller I, Winkler H (1995): Effects of haloperidol, clozapine and citalopram on messenger RNA levels of chromogranins A and B and secretogranin II in various regions of rat brain. Neuroscience 69:881-891

Le Moine C, Normand E, Bloch B (1991): Phenotypical characterization of the rat striatal neurons expressing the D1 dopamine receptor gene. Proc Natl Acad Sci USA 88:4205-4209

Leysen JE, Janssen PM, Schotte A, Luyten WH, Megens AA (1993): Interaction of antipsychotic drugs with neurotransmitter receptor sites in vitro and in vivo in relation to pharmacological and clinical effects: Role of 5HT2 receptors. Psychopharmacology (Berl) 112:S40-S54

Lieberman JA, Sheitman BB, Kinon BJ (1997): Neurochemical sensitization in the pathophysiology of schizophrenia: Deficits and dysfunction in neuronal regulation and plasticity. Neuropsychopharmacology 17:205-229

MacArthur L, Eiden L (1996): Neuropeptide genes: targets of activity-dependent signal transduction. Peptides 17:721-728

Mahata SK, Mahata M, Marksteiner J, Sperk G, Fischer-Colbrie $R$, Winkler $H$ (1991): Distribution of mRNAs for chromogranin A and B and secretogranin II in rat brain. Eur J Neurosci 3:895-904

Mahata SK, Mahata M, Parmer RJ, O'Connor DT (1999): Desensitization of catecholamine release. The novel catecholamine release-inhibitory peptide catestatin (chromogranin a344-364) acts at the receptor to prevent nicotinic cholinergic tolerance. J Biol Chem 274:2920-2928

Marin C, Engber TM, Bonastre M, Chase TN, Tolosa E (1996): Effect of long-term haloperidol treatment on striatal neuropeptides: Relation to stereotyped behavior. Brain Res 731:57-62

Marksteiner J, Kirchmair R, Mahata SK, Mahata M, FischerColbrie R, Hogue-Angeletti R, Saria A, Winkler H (1993a): Distribution of secretoneurin, a peptide derived from secretogranin II, in rat brain: An immunocytochemical and radioimmunological study. Neuroscience 54:923-944

Marksteiner J, Saria A, Miller CH, Krause JE (1993b): Increased synthesis of neurokinin B and enkephalin after chronic haloperidol treatment. Regul Pept 46:349-351

Marksteiner J, Sperk G (1988): Concomitant increase of somatostatin, neuropeptide $\mathrm{Y}$ and glutamate decarboxylase in the frontal cortex of rats with decreased seizure threshold. Neuroscience 26:379-385

Mercugliano M, Chesselet MF (1992): Clozapine decreases enkephalin mRNA in rat striatum. Neurosci Lett 136:10-14

Mijnster MJ, Ingham CA, Meredith GE, Docter GJ, Arbuthnott GW (1996): Morphological changes in met(5)enkephalin-immunoreactive synaptic boutons in the rat neostriatum after haloperidol decanoate treatment. Eur J Neurosci 8:716-726

Mijnster MJ, Schotte A, Docter GJ, Voorn P (1998): Effects of risperidone and haloperidol on tachykinin and opioid precursor peptide mRNA levels in the caudate-putamen and nucleus accumbens of the rat. Synapse 28:302-312

Needham PL, Atkinson J, Skill MJ, Heal DJ (1996): Zotepine: Preclinical tests predict antipsychotic efficacy and an atypical profile. Psychopharmacol Bull 32:123-128

Nguyen TV, Kosofsky BE, Birnbaum R, Cohen BM, Hyman SE (1992): Differential expression of c-Fos and Zif268 in rat striatum after haloperidol, clozapine, and amphetamine. Proc Natl Acad Sci USA 89:4270-4274

Normand E, Popovici T, Fellmann D, Bloch B (1987): Anatomical study of enkephalin gene expression in the rat forebrain following haloperidol treatment. Neurosci Lett 83:232-236

O'Donnell P, Grace AA (1998): Dysfunctions in multiple interrelated systems as the neurobiological bases of schizophrenic symptom clusters. Schizophr Bull 24:267-283

Paxinos G, Watson C (1986): The rat brain in stereotaxic coordinates, 2nd ed. Sydney, Academic Press

Robertson GS, Fibiger HC (1992): Neuroleptics increase c-fos expression in the forebrain: Contrasting effects of haloperidol and clozapine. Neuroscience 46:315-328

Robertson GS, Fibiger HC (1996): Effects of olanzapine on regional C-Fos expression in rat forebrain. Neuropsychopharmacology 14:105-110

Robertson GS, Matsumura H, Fibiger HC (1994): Induction patterns of Fos-like immunoreactivity in the forebrain 
as predictors of atypical antipsychotic activity. J Pharmacol Exp Ther 271:1058-1066

Romano GJ, Shivers BD, Harlan RE, Howells RD, Pfaff DW (1987): Haloperidol increases proenkephalin mRNA levels in the caudate-putamen of the rat: A quantitative study at the cellular level using in situ hybridization. Brain Res 388:33-41

Schotte A, Janssen PF, Gommeren W, Luyten WH, Van GP, Lesage AS, De LK, Leysen JE (1996): Risperidone compared with new and reference antipsychotic drugs: In vitro and in vivo receptor binding. Psychopharmacology (Berl) 124:57-73
Selemon LD, Goldman-Rakic PS (1999): The reduced neuropil hypothesis: A circuit based model of schizophrenia. Biol Psychiatry 45:17-25

Shen PJ, Gundlach AL (1996): Chromogranin mRNA levels in the brain as a marker for acute and chronic changes in neuronal activity: Effect of treatments including seizures, osmotic stimulation and axotomy in the rat. Eur J Neurosci 8:988-1000

Thiele C, Huttner WB (1998): The disulfide-bonded loop of chromogranins, which is essential for sorting to secretory granules, mediates homodimerization. J Biol Chem 273:1223-1231 